\title{
“Études littéraires”, Le carnet pour lui-même, dir. F. Dumont
}

\section{Carminella Biondi}

\section{(2) OpenEdition}

10 Journals

\section{Édition électronique}

URL : https://journals.openedition.org/studifrancesi/21834

DOI : 10.4000/studifrancesi.21834

ISSN : 2421-5856

Éditeur

Rosenberg \& Sellier

\section{Édition imprimée}

Date de publication : 1 décembre 2019

Pagination : 621-622

ISSN : 0039-2944

\section{Référence électronique}

Carminella Biondi, «"Études littéraires", Le carnet pour lui-même, dir. F. Dumont », Studi Francesi [En ligne], 189 (LXIII | III) | 2019, mis en ligne le 01 mars 2020, consulté le 11 novembre 2021. URL : http:// journals.openedition.org/studifrancesi/21834 ; DOI : https://doi.org/10.4000/studifrancesi.21834

Ce document a été généré automatiquement le 11 novembre 2021.

\section{(c) (i) (9)}

Studi Francesi è distribuita con Licenza Creative Commons Attribuzione - Non commerciale - Non opere derivate 4.0 Internazionale. 


\title{
“Études littéraires", Le carnet pour lui-même, dir. F. Dumont
}

\author{
Carminella Biondi
}

\section{RÉFÉRENCE}

“Études littéraires”, Le carnet pour lui-même, dir. F. Dumont, vol. 48, n. 1-2, 2019, 202 pp.

1 Ce numéro des “Études littéraires”, publiées par l'Université Laval, se penche sur un «genre», celui des carnets, qui a été généralement considéré comme marginal et propédeutique à l'œuvre qui va suivre. Le regard qu'on se propose d'y porter ici est tout à fait inédit, comme le souligne le directeur de l'ouvrage dans sa «Présentation»: «l'orientation commune des études ici rassemblées est de considérer le carnet pour luimême, comme une œuvre à part entière, qui aurait trouvé dans cette forme sa juste tonalité» (p. 8). La présentation est suivie d'un texte d'Andrei Minzetanu (auteur d'un livre sur le sujet, Carnets de lecture. Généalogie d'une pratique littéraire, 2016), «Le carnet du lettré: objet matériel, objet mental» (pp.13-18), qui en éclaire la perspective théorique, en essayant de définir le genre, de dresser un bilan des différents types de carnet et des genres similaires, et surtout de convaincre le lecteur de l'importance heuristique de ce regard nouveau sur un genre marginalisé. Suivent quatre études consacrées à ceux qui sont définis des «devanciers»: Marc-Aurèle, Sei Shônoghan, Montaigne et Joubert, pour arriver enfin aux auteurs des $\mathrm{xx}^{\mathrm{e}}-\mathrm{XxI}^{\mathrm{e}}$ siècles, parmi lesquels on compte quelques écrivains de la francophonie hors-hexagonale. On y trouve d'abord un auteur inattendu, Aimé Césaire, car on a toujours considéré l'ouvrage dont il est question comme l'un des grands chefs-d'œuvre de la poésie du $\mathrm{xx}^{\mathrm{e}}$ siècle: Poétique du carnet dans "Cahier d'un retour au pays natal" d'Aimé Césaire, d'Olga El-Bongo (p. 119-136). La lecture qui est proposée ici vise à mettre en lumière la présence du «je» de l'auteur à l'intérieur de l'œuvre, en récupérant le «travail minutieux de matières composites et très composées, mises en lambeaux puis recomposées en un langage plus proche à la vérité du poète» (p. 122) et sollicite la discussion, voire même la critique sévère, mais nous oblige aussi à jeter un regard nouveau sur un texte qu'on n'aurait pas cru 
susceptible d'une lecture carnettiste. Par contre, la volonté de l'écrivain québécois André Major de s'inscrire dans ce genre ne fait aucun doute, ainsi que le démontrent les titres de ses ouvrages et l'analyse convaincante de Michel Biron: Le fil du carnet chez André Major (pp. 153-162). En 1997, Major, qui était alors un romancier très connu et un réalisateur d'émissions littéraires à Radio-Canada, désavoue le roman et décide de privilégier le carnet, et une forme particulière de carnet, ainsi que le souligne Michel Biron, qui «se distingue très nettement [...] de l'autobiographie, dont il se méfie autant sinon davantage que du roman» (p. 154). Major veut faire du carnet un témoin de son époque, une forme d'écriture qui vise le réel: «La désertion se retourne ainsi en son envers, devient une forme d'engagement dans l'écriture et dans la vie "élargie", liant organiquement le geste d'écrire et le métier de vivre» (p. 162). Avec Major le carnet devient donc véritablement une œuvre littéraire à part entière. On peut en dire autant d'un autre déserteur, un «déserteur» double, car il a longtemps abandonné la France pour le Québec et la poésie pour le carnet de notes: Jean-Pierre Issenuth, auquel Thomas Manguy consacre un essai au titre apparemment paradoxal pour un «transfuge», mais qui indique, par contre, le solide rapport de l'auteur à la réalité, quel que soit le lieu où il se trouve à vivre (L'enracinement de Jean-Pierre Issenuth, pp. 165-175). Manguy insiste sur la prise de distance de la poésie, qu'il avait pratiquée dans sa jeunesse, de la part d'Issenuth, et surtout sur son refus de l'exhibitionnisme qui caractérise le monde des lettres, en particulier des lettres québécoises, un monde renfermé sur lui-même, ayant perdu tout rapport avec le monde réel, qui reste au contraire fondamental pour l'écrivain. En effet, pour lui «les mots doivent demeurer une voie d'accès au monde, une médiation efficace qui l'aide à mieux se situer au milieu des choses» (p. 168). Le dernier essai du recueil, Penser les carnets numériques d'écrivain: écritures médiatisées et réinvestissement de l'idée de publication (pp.177-190), de René Audet, tout en s'occupant des carnets numériques, s'efforce aussi de comprendre le rôle du support et des matériaux utilisés dans cette «écriture constamment en mouvement» (p.182), où se réalise au plus haut niveau la pratique de l'hypertextualité: «ces sites, riches et labyrinthiques, sont le théâtre d'une mise en réseau continuelle, au sens de maillages (sémantiques, hypertextuels, thématiques) que l'écrivain peut établir entre des articles et des contenus déjà publiés» (p. 182). Quelques-uns de ces carnettistes numériques sont canadiens, tels Philippe de Jonckheere, Audrée Wilhelmy, Zviane, Jimmy Beaulieu, Samuel Cantin, Patrick Beaulieu, Daniel Canty.

2 Je ne saurais dire si le projet de ces mélanges aura une suite, si cette tentative de démarginaliser un genre mineur changera le panorama de la critique littéraire ou ne restera que l'une des nombreuses tentatives de fixer de nouveaux paradigmes à la littérature erratique du «chaos monde», mais la lecture en est sans aucun doute stimulante. 